\title{
The effect of mercerization process on the structural and morphological properties of Pineapple Leaf Fiber (PALF) pulp
}

\author{
Nadirul Hasraf Mat Nayan, Wan Aizan Wan Abdul Rahman* and Rohah Abdul Majid \\ Department of Polymer Engineering, Faculty of Chemical Engineering, UTM, 81310 Skudai, Johor, Malaysia \\ *Corresponding Author: w.aizan@cheme.utm.my (W.A.W.A. Rahman)
}

\section{Article history :}

Received 3 January 2013

Revised 15 March 2013

Accepted 29 June 2013

Available online 1 August 2013

\section{GRAPHICAL ABSTRACT}

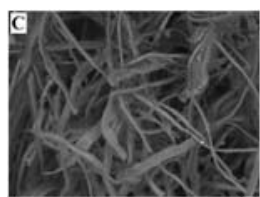

Mercerized PALF treated with $\mathrm{NaOH}$

\begin{abstract}
Environmental awareness and depletion of the wood resources are among vital factors that motivate various researchers to explore the potential of agro-based crops as an alternative source of fiber material in paper industries such as writing, printing, wrapping, and packaging. Fibers from agro-based crops are available in abundance, low cost, and most importantly its biodegradability features, which sometimes referred as "ecofriendly" materials. This paper attempt to study the effect of mercerization treatment on the structural and morphological properties of pineapple leaf fiber (PALF) pulp. It was shown that the PALF pulp achieved favourable structural and morphological properties as characterized by FTIR spectroscopy, X-ray diffractometer and scanning electron microscope (SEM). The mercerized fibers $(15 \%$ $\mathrm{NaOH})$ achieved the best tensile properties compared to that of pristine fibers. This modification have the potential to be utilized as pulp for paper based products.
\end{abstract}

Keywords: Pineapple leaf pulp, Mercerization, Morphological, Structural

(C) 2014 Penerbit UTM Press. All rights reserved http://dx.doi.org/10.11113/mjfas.v10n1.63

\section{INTRODUCTION}

Present-day, the center of research in the field of paper science and technology has been aimed on developing papers for writing, printing, wrapping, packaging, and many other paper products from renewable resources, mostly the abundantly available agro-waste and lignocellulosic materials. A vast number agro-waste and lignocellulosic materials that have both economic and environmental benefits are being considered for application in pulp and paper industries. Growing environmental awareness and depletion of the wood resources worldwide are among the vital factors that motivated academia to explore the potential of agro-waste crops and lignocellulosic materials as the alternative source of fiber material in pulp and paper industries. Within the past few years, there has been a tremendous increase in the use of natural fibers as source of fiber for pulp and paper [1]. The potential of natural fiber-based paper using jute, kenaf, hemp, coir, sisal, pineapple, etc., has received numerous attentions among researchers worldwide for their excellent specific properties [2]. Therefore, the availability of abundantly inexpensive lignocellulosic natural fibers, such as pineapple leaf fiber (PALF) in tropical countries, such as Malaysia, provides a unique opportunity of exploring the possibility of its utilization as an inexpensive raw material for pulp and paper applications.

PALF is leaves of the plant, Anannus comosus, originating to the Bromeliaceae family. The pineapple plant has a very short stem which first produces a rosette of leav but which latter elongated and bears numerous spirally arranged fibrous leaves. The leaves are sword shaped and approximately 3 feet long, 2 to 3 inch wide [3]. In addition, the leaves are dark green in colour and bear spines of claws on their margins. The leaves of the pineapple plant yield strong, white fine silky fibers [4]. The fibers are obtained by either mechanical means or retting the leaves in water and fresh leaves yield about 2 to $3 \%$ of fiber [5]. PALF is largely cultivated in Malaysia, mainly for its fresh consumption, canning and juicing. Its cultivation in Malaysia is substantial and in 2010 alone about 25, 100 hectares of land is cultivated [6]. With 648, 193 metric tonnes or $5.3 \%$ of the world pineapple production, Malaysia currently stood at the ninth position for the production and its export to the world market [7]. However, with increasing pineapple production, pineapple wastes, are also proportionally increasing. Waste disposal raises a growing concern since it is usually prone to microbial spoilage and it causes serious environmental problems. The utilization of waste, such as PALF, would provide an innovation to handle the great deal of waste from processing. 
Chemically, PALF is multicellular lignocellulosic in nature. The major constituents of PALF comprises of mainly cellulose (70-82\%), hemicellulose (10-16\%), and lignin $(5-12 \%)$ [8]. Due to its high cellulose content, PALF exhibited superior mechanical properties [9]. PALF is of fine quality, and unlike other agro-waste, its structure is without mesh [10]. It has a ribbon-like structure and is cemented together by gummy matters known as lignin, which contribute to the strength of the fiber [11]. On the other hand, PALF filaments are well separated and it is two and half times more extensible, with superior fiber bundle strength [12]. However, although PALF are known to have excellent specific properties as mentioned before, majority of these pineapple leaves are still going to waste because of lack of knowledge about their economic applications. Therefore, profound research has to be done to discover the potential applications of PALF, and one way to utilize this natural resource is to convert it into pulp and paper.

Mercerization or sometimes referred to as alkali treatment is the process of subjecting a cellulose fiber to an interaction with a relatively concentrated aqueous solution of a strong base [13], with the objective of producing sufficient swelling, thus, resulted in a reduction of linear density, shrinkage in dimension and more visible fibrillar structure of a fiber, as well as change in mechanical properties considerably depending on the treatment time and concentration of alkali solution. For cellulose fibers, hemi-cellulose has shown to be very sensitive to the action of caustic soda, which exerts only a slight effect on lignin or cellulose [14]. The effects of mercerization on the suitability to mechanical treatment, prominent tensile strength, of cellulose fibers have been extensively studied. From previous research, it was reported that chemically modified PALF with alkali treatment of caustic soda leads to a significant increase in tensile strength when compared to other techniques [15].

In the present research, an attempt was made to explore: (i) the effect of distinct caustic soda $(\mathrm{NaOH})$ solution concentration on the properties of produced PALF pulps and (ii) the effect of mercerization on the properties of the prepared PALF pulps. The structural and morphological of the prepared PALF pulps were examined by using scanning electron microscopy and X-ray diffraction.

\section{EXPERIMENTAL}

The materials used for the study includes pineapple leaf fibers, collected from FIMA pineapple plantation estate in Ayer Baloi district of Pontian province, Malaysia, and caustic soda $(\mathrm{NaOH})$, obtained from Merck and Co., Inc. Each leaf was individually separated and cleaned by hand, and then stored at temperature of $4^{\circ} \mathrm{C}$ in a refrigerator, prior use in the experiments. PALF were chopped into uniform size of approximately $10 \mathrm{~cm}$. The fibers were treated with $10 \%, 15 \%$ and $20 \% \mathrm{NaOH}$ aqueous solution $(\mathrm{w} / \mathrm{v})$ in beakers and continuously stirred for a period of $24 \mathrm{~h}$ at room temperature. Later these mercerized fibers were washed several times distilled water until the alkali was rid of. Then the mercerized fibers were washed with $1 \% \mathrm{HCl}$ solution to neutralize the remaining alkali, followed by rinsing with distilled water until the mercerized fibers are neutral. After that, the mercerized fibers were dried in a vacuum oven at temperature of $60^{\circ} \mathrm{C}$ for $24 \mathrm{~h}$ and then further dried in a drying oven at $100^{\circ}$ for $1 \mathrm{~h}$. FTIR spectra of the unmercerized and mercerized fibers were obtained from $\mathrm{KBr}$ disc of samples using a Perkin Elmer infrared spectrometer with a resolution of $0.4 \mathrm{~cm}^{-1}$. The structure and morphology of the un-mercerized and mercerized fibers were observed at $1000 \mathrm{x}$ magnifications by using a scanning electron microscope (SEM), Philips XL40, at an accelerating voltage of $10 \mathrm{kV}$. The X-ray diffraction profiles of the unmercerized and mercerized fibers were obtained by using $\mathrm{Cu} \mathrm{K} \alpha$ radiation $(\lambda=0.154 \mathrm{~nm})$, generated with Philips diffractometer $(45 \mathrm{kV}, 100 \mathrm{~mA})$ at scanning rate of $0.02 \mathrm{~s}^{-1}$ in the $2 \theta$ range from 2 to $90^{\circ}$. The crystalline index of cellulose, $\mathrm{C}_{\mathrm{Ir}}$ was calculated using $\left(I_{002}-I_{\mathrm{am}} / I_{002}\right) \times 100$ (Segal et. al., 1959), where, $I_{002}$ is the peak intensity of cellulose $I\left(\mathrm{C}_{\mathrm{I}}\right)$ and $I_{\mathrm{am}}$ is the peak intensity of the amorphous fraction. The fiber bundle tensile tests were performed using an Instron Tensile Testometric machine with crosshead speed of $1 \mathrm{~mm} / \mathrm{min}$ at room atmosphere of $23{ }^{\circ} \mathrm{C}$. The un-mercerized and mercerized PALF were cut into $60 \mathrm{~mm}$ lengths and separated into individual fiber bundle. The gauge length was approximately $25 \mathrm{~mm}$. 15 replications were done for each fiber type. The gripping technique was in accordance to ASTM D3822. The unit break $(\mathrm{N} / \mathrm{mm} 2)$ is calculated using $\mathrm{F} / \mathrm{A}$; where, $\mathrm{F}$ is the maximum breaking load and $\mathrm{A}$ is the cross sectional area of the fibers. Prior to all the measurements, the specimens were conditioned at $100^{\circ} \mathrm{C}$ for $1 \mathrm{~h}$ and cooled down in desiccators.

\section{RESULTS \& DISCUSSION}

\subsection{X-ray diffraction}

Fig. 1 shows the XRD patterns of the un-mercerized and mercerized PALF with different $\mathrm{NaOH}$ concentrations. All the PALF specimens reveal crystallinity peak of native cellulose, the $\mathrm{C} 1$ peaks $(2 \theta=23.0,002$ plane [16]. For the un-mercerized PALF, the $\mathrm{C}_{\mathrm{Ir}}$ is not available. This is contributed by the present of enormous amount of lignin. Major portion the specimen is covered by amorphous lignin that inhibits the diffraction of the cellulose component. This can be observed by the lower intensity of [002] peak compared to that of the amorphous peak. Meanwhile CIr for 10 and $15 \%$ mercerized PALF are found to be 53.8 and $62.5 \%$, respectively. This clearly demonstrates the increase in the degree of crystallinity of PALF after removal of unwanted impurities and lignin. Furthermore, no new peaks are observed for the 10 and $15 \%$ mercerized PALF. This indicates that no crystalline transformation of PALF structure occurred with $\mathrm{NaOH}$ treatment. However, an increased in the $\mathrm{NaOH}$ concentration up to $20 \%$ reduced 
the [002] peak reaching an intensity value equal to that of amorphous peak. This is may be due to high concentration of $\mathrm{NaOH}$ which leads to fibers deterioration and ruptures that reduced the $\mathrm{C} 1$ peak intensity.

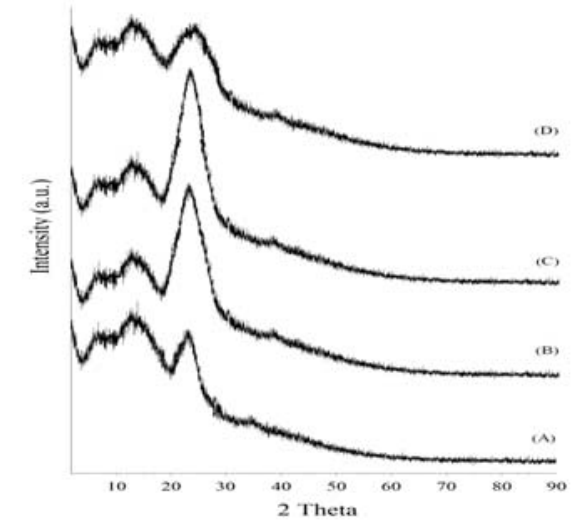

Fig. 1 X-ray diffraction profiles of the (A) un-mercerized and mercerized PALF treated with (B) $10 \%$, (C) $15 \%$, and (D) $20 \%$ $\mathrm{NaOH}$ concentrations.

\section{$3.2 \quad$ FTIR spectroscopy}

The un-mercerized and $\mathrm{NaOH}-$ mercerized PALF were characterized by FTIR spectra. The FTIR absorption characteristic feature of PALF (Fig. 2) is due to its lignin and hemicellulose components which present in the fibers [17]. From the FTIR absorption pattern of un-mercerized PALF (Fig. 2A) mercerized PALF (Fig. 2B), the following peaks have been observed. The strong broad peak at 3200$3600 \mathrm{~cm}^{-1}$ in the spectrum of PALF is the characteristics of hydrogen-bonded $\mathrm{OH}$ stretching vibrations, which represents the intermolecular and intramolecular $\mathrm{H}$ bond of free $\mathrm{OH}$ of cellulose [18]. The strong peak at $2900 \mathrm{~cm}^{-1}$ corresponds to the $\mathrm{CH}$ stretching vibrations [19]. The peak at $1730 \mathrm{~cm}^{-1}$ is the characteristic band for carbonyl $(\mathrm{C}=\mathrm{O})$ stretching. It is noticeable that, with mercerization treatment, this band disappears (Fig. 2B). It appears that during mercerization, a substantial portion of uranic acid, a constituent of hemicellulose xylan, is removed [20]. Thus, resulting in the disappearance of this peak. Meanwhile, the band near $1245 \mathrm{~cm}^{-1}$ which can be seen in un-mercerized PALF spectra (Fig. 2A) does no longer exist in mercerized PALF specimens. This absorption band represents the stretching aryl group in lignin. This indicated that the removal of lignin was achieved.

\subsection{Tensile test}

The tensile strength of the un-mercerized PALF bundle corresponds well with previously reported works (Fig. 3) [21-22]. As shown in Fig. 3, the mercerized PALF exhibited better tensile properties than the un-mercerized PALF. Treatment with $\mathrm{NaOH}$ increases the tensile strength of mercerized PALF due to the removal of impurities and poor crystalline structure of hemicelluloses and lignin. The increment in tensile strength of the mercerized PALF was also contributed by the mechanism of mercerization itself. This is because, during mercerization, swelling of native cellulosic materials in the $\mathrm{NaOH}$ solution, which is the main polymorphic modification of cellulose in the composites, causes a rearrangement of the crystal packing of chains from native cellulose I to cellulose II, as clearly exhibits in the X-ray diffraction spectrum (Fig. 1) of the un-mercerized and mercerized PALF. A significant increment pattern can also be observed in Fig. 3. The enhancement is presumably related to a better efficiency improvement in interfacial properties of the mercerized PALF as revealed by the scanning electron micrographs (Fig. 4).The strength of the mercerized PALF specimens treated at $20 \% \mathrm{NaOH}$ concentration, however, reduced tremendously compared to un-mercerized PALF. This can be attributed to the fibers deterioration and ruptures which can be clearly seen in micrograph of the fiber surfaces. On the other hand, mercerized PALF specimens treated with $\mathrm{NaOH}$ concentrations below $20 \%$ seemed to retain its mechanical integrity.

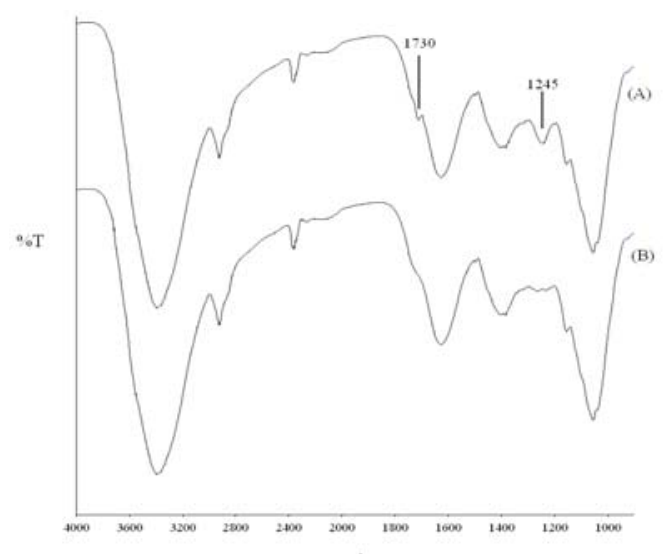

Fig. 2 IR spectrum of PALF: (A) un-mercerized and the (B) mercerized fiber treated $15 \% \mathrm{NaOH}$ concentration in solution

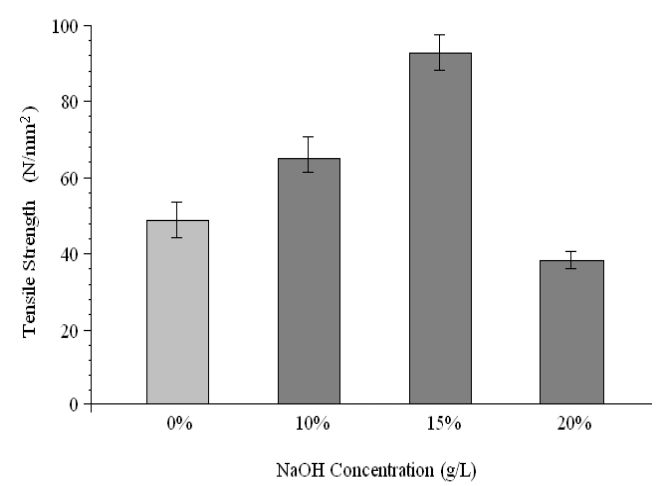

Fig. 3 Tensile strength of un-mercerized and mercerized PALF treated with distinct $\mathrm{NaOH}$ concentrations.

3.4 Scanning electron microscope 
The changes of the surface features of PALF obtained from SEM are shown in Fig. 4. The micrograph of the un-mercerized fiber (Fig. 4A) shows their multicellular nature. The fibrillar structure as well as porosity of the individual fibers is revealed on fiber However, in Fig. 4B, where the fibers are mercerized, fibrillar structure is obvious and dense due to better dissolution of wax and gummy materials [23]. From the scanning electron micrographs (Fig. 4B-4D), it is obvious that mercerization results in a rough surface topography, and it can also be seen that with increasing $\mathrm{NaOH}$ concentration the fibers in PALF are becoming more and more exposed. So, it can be suggested that mercerization result in fiber fibrillation. Fibrillation is the breaking down of the composite fiber bundle into smaller fibers, which leads to a decrease in the spiral angle, i.e., closer to the fiber axis [24] and hence there is an increase in molecular orientation. From the

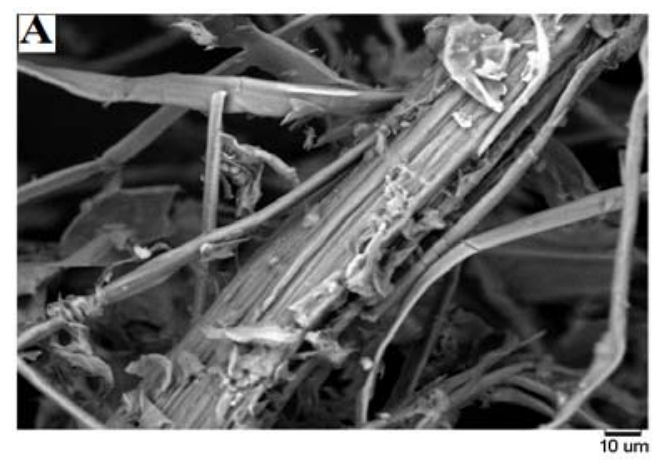

Fig. 4A Scanning electron micrographs of surface of unmercerized PALF

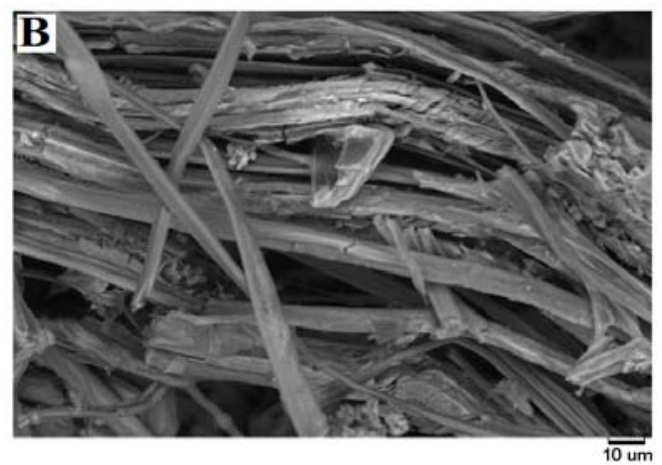

Fig. 4B Scanning electron micrographs of surface of mercerized PALF treated with $10 \% \mathrm{NaOH}$ concentration

\section{CONCLUSION}

The PALF were treated with different concentrations of $\mathrm{NaOH}$ solution. Effects of these different $\mathrm{NaOH}$ concentrations on the physical and morphological properties of PALF were studied. It was observed that $\mathrm{NaOH}$ treatments have significant influence on the physical and morphological properties of the PALF. IR spectroscopy and SEM were used to characterize the PALF scanning electron micrograph of un-mercerized PALF (Fig. 4A), it can be observed that each unit cell of fiber consists of small cellulose microfibrils which are surrounded and adhered together with lignin and hemicellulose. During mercerization, this total structure that produce continues fiber was broken down, thus splitting the fiber into finer filament which can be clearly observed in Fig. 4B and 4C.

However, it is also observable that the mercerized PALF shown fine filament properties up to $15 \% \mathrm{NaOH}$ concentration, after which an increment in $\mathrm{NaOH}$ concentration during mercerization causes enormous reduction in fiber properties (Fig. 4D). This is may be attributed by the fact that the alkali sensitive bonds existing in the different component of PALF are subjected to rupture and deterioration as a result of penetration of alkali, causing components like hemicellulose starts to get depleted [25].

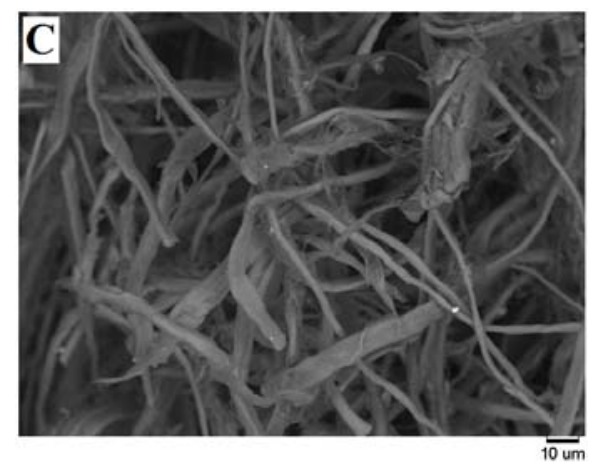

Fig. 4C Scanning electron micrographs of surface of mercerized PALF treated with $15 \% \mathrm{NaOH}$ concentration

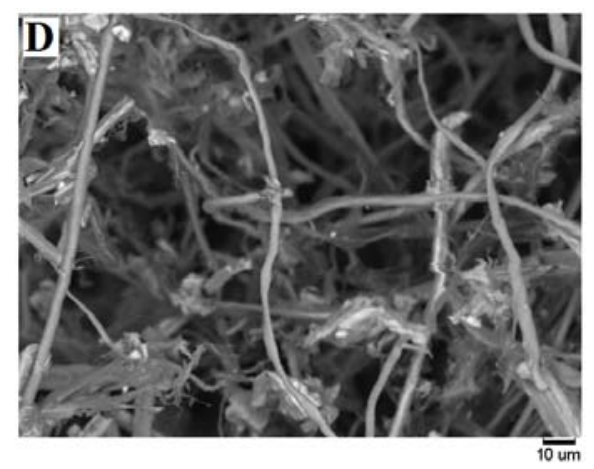

Fig. 4D Scanning electron micrographs of surface of mercerized PALF treated with $20 \% \mathrm{NaOH}$ concentration

surface. Mercerized PALF showed rough surface topography and increased fiber aspect ratio. The loss of cementing material results in a more oriented and closely spaced fiber that results in more exposed cellulose due to mercerization as shown by the XRD patterns. But at the high $\mathrm{NaOH}$ concentration, the cellulose chains deteriorate, as a result of penetration and swelling of $\mathrm{NaOH}$ through the fiber. The tensile of mercerized PALF showed increment compared to un-mercerized PALF, but, at the high $\mathrm{NaOH}$ 
concentration, the cellulose chains deteriorate, as a result of penetration and swelling of $\mathrm{NaOH}$ through the fiber.

\section{ACKNOWLEDGEMENT}

The authors thank the Department of Polymer Engineering and Ibnu Sina Institute, Universiti Teknologi Malaysia, Johor for the laboratory facilities and technical support given throughout the research work, as well as gratitude to Ministry of Higher Education (MOHE) for providing research grants VOT Q.J130000.7125.00H07 and Research Management Center-UTM (UTM-RMC) for managing the fund.

\section{REFERENCES}

[1] S. J. Eichhorn, C. A. Baillie, N. Zafeiropoulos, L. Y. Mwaikambo, M. P. Ansell, and A. Dufresne, J. Mater. Sci., 36 (2001) 107.

[2] F. Nagota, and H. Takahashi, Compos. Eng., 5 (1995) 743.

[3] M. Misra, A. K. Mohanty, and L. T. Drzal, Polym. Mater. Sci. Eng., 85 (2000) 299.

[4] A. K. Bledzki, S. Reihmane, and J. Gassan, J. Appl. Polym. Sci., 59 (1996) 329.

[5] R. K. Samal, and M. Bhuyan, J. Appl. Polym. Sci. 52 (1994) 675

[6] R. M. N. Arib, M. S. Sapuan, M. A. M. M. Hamdan, and H. M. D. K. Zaman, Polym. Compos., 12 (2010) 341.

[7] A. V. Tran, Ind. Crop. Prod., 24 (2006) 66.
[8] S. Mishra, A. K. Mohanty, L. T. Drzal, M. Misra, and G. Hinrichsen, Macromol. Mater. Eng., 48 (2004) 285.

[9] L. U. Devi, S. S. Bhagawan, and S. Thomas, J. Appl. Polym. Sci., 64 (1997) 739

[10] J. Gassan, and A. K. Bledzki, J. Appl. Polym. Sci., 71 (1999) 623.

[11] S. Mishra, M. Misra, S. S. Tripathy, S. K. Nayak, and A. K. Mohanty, J. Reinf. Plast. Compos., 20 (2001) 321.

[12] M. Das, A. Pal, and D. Chakraborty, J. Appl. Polym. Sci., 100 (2006) 238.

[13] S. Luo, and A. N. Netravali, Polym. Compos., 20 (1999) 367.

[14] W. Liu, M. Misra, P. Askeland, L. T. Drzala, and A. K. Mohanty, Bioresource Technol., 46 (2005) 710.

[15] R. K. Samal, and M. C. Ray, J. Appl. Polym. Sci., 64 (1997) 119.

[16] S. Park, J. O. Baker, M. E. Himmel, P. A. Parilla, and D. K. Johnson, Biotechnol. Progr., 3 (2010) 1.

[17] R. K. Samal, and M. Bhuyan, J. Appl. Polym. Sci., 52 (1994) 675.

[18] S. I. A. Razak, W. A. W. A. Rahman, S. Hashim, and M. Y. Yahya, Compos. Interf., 19 (2012) 365.

[19] V. L. Chiang, H. J. Cho, R. J. Puumala, R. C. Eckert, and W. S. Fuller, Tappi J., 70 (1987) 101.

[20] A. K. Mohanty, M. Misra, and L. T. Drzal, Polym. Polym. Compos., 86 (2002) 341.

[21] J. George, S. S. Bhagawan, and S. Thomas, Compos. Interf., 19 (2012) 793.

[22] L. Segal, L. Creely, A. E. Martin, and C. M. Conrad, Text. Res. J., 29 (1969) 786

[23] A. K. Bledzki, and J. Gassan, Prog. Polym. Sci., 24 (1999) 221.

[24] J. Gassan, and A. K. Bledzki, Compos. Sci. Technol., 59 (1999), 303.

[25] M. Das, and D. Chakraborty, J. Appl. Polym. Sci., 107 (2008) 522. 